\title{
Patients' Perspectives: Understanding of Medical Prescription
}

\section{Nyein Chan*, Kaung Su Lin, Nyein Chan Aung, Moe Kyaw, Myat Khaing, Tin Moe Mya, Khin Phyu Pyar and Tin Maung Hlaing}

Defence Services Medical Research Centre, Tat Kone Township, Naypyitaw, Myanmar

\begin{abstract}
A cross-sectional descriptive study was conducted among participants who attended to outpatient department Number 2 Defence Services General Hospital. The objective is to describe understanding of prescription from health care providers to patients. The study recruited participants by using simple random sampling and pre-tested questionnaire from August to September 2014. The participants were age between 17 and 77 years and the mean age was 47.27 (SD 11.67) years. Among 194 participants, $99(51 \%)$ were male and $95(49 \%)$ were female. The participants who came to hospital for themselves $(93.3 \%)$, for husband/wife $(2.1 \%)$, for their children $(1 \%)$ and for parent $(3.6 \%)$. The participants who went to the specialist doctors $(59.3 \%)$ and medical officer $(25.8 \%)$ and the remainders $(14.9 \%)$ did not know which doctors treated to them. Although the participants $(87.6 \%)$ could answer their diagnosis, $12.4 \%$ of participants could not answer it. The time given for explanation of prescription was between 1 and 20 minutes and the mean time was 5.5 (SD 4.26) minutes. While $68 \%$ of the participants could answer at least one pill of the prescribed drugs, $32 \%$ of participants could not answer it. Furthermore, the participants (87.6\%) knew well about dosing frequency of pills that they took. But $4.6 \%$ of participants knew about dosing frequency of one or more pills and the remainders $(7.7 \%)$ did not know about it. Most of the prescribers $(74.7 \%)$ did not explain adverse reaction of pills; only $25.3 \%$ of prescribers explained it. There was association between patients' understanding of medical prescription and age group and gender. Despite the doctors and nursing staffs prescribing clearly and giving more time for explanation of prescription, some of the participants do not know it. Thus, the prescribers should ask how to take the pills after the patients had received the pills and explain well about the adverse reaction of the pills.
\end{abstract}

Keywords: Prescription; Pill

\section{Introduction}

The World Health Organization (WHO) defines adherence as "the extent to which a person's behavior - taking medication, following a diet, and/or executing lifestyle changes - corresponds with agreed recommendations from a health care provider [1]." Therapeutic adherence is determined by persistence and compliance of medication intake. Persistence describes the length of time a patient continues taking medication and is measured as the time from treatment initiation to treatment completion or discontinuation. Compliance describes how well a patient is taking his or her medication, that is, to what extent a patient follows a treatment regimen and any associated dosing requirements [2]."

According to the WHO, in developed countries, adherence to longterm therapies for chronic diseases averages 50 percent [2]. "Research in the medical and social sciences has demonstrated that across a wide variety of settings and treatment recommendations, roughly half of all medical patients in the United States do not adhere to, or comply with, their physicians' advice. Close to $40 \%$ of patients take prescribed medication incorrectly or not at all [3]."

For more than three decades, researchers have sought to understand and improve patients' understanding to medication regimens for the treatment of illness [4]. Their findings suggest a number of strategies that healthcare providers can use to improve patients' understanding. A physician, nurse practitioner or other authorized healthcare provider who writes a prescription usually intends that the patient follows it. However, given the extent of poor understanding, it is unlikely that any prescriber will see perfect adherence by all patients [5].

According to above literatures, misunderstanding of medical prescription still occur in community and it may cause complications upon them such as antibiotic resistance and recurrence of the disease.
Therefore, assessment of understanding of medical prescription is still needed. This study aims to explore understanding of medical prescription from health care provider to the patients and its influencing factors upon them. Moreover, this study may support important facts for further plan in medical prescription.

\section{Objectives}

\section{General objective}

To find out understanding of prescription from health care providers to patients

\section{Specific objectives}

1. To describe the social characteristics of participants,

2. To find out perception of participant about drug prescription from health care providers,

3. To describe understanding of prescription from health care providers to patients,

4. To find out the association between patients' understanding of medical prescription and influencing factors.

*Corresponding author: Nyein Chan, Defence Services Medical Research Centre, Tat Kone Township, Naypyitaw, Myanmar, E-mail: nyeinchan.dsmrc@ gmail.com

Received August 25, 2015; Accepted February 10, 2016; Published February 18, 2016

Citation: Chan N, Lin KS, Aung NC, Kyaw M, Khaing M, et al. (2016) Patients Perspectives: Understanding of Medical Prescription. J Gen Pract 4: 233. doi 10.4172/2329-9126.1000233

Copyright: () 2016 Chan N, et al. This is an open-access article distributed under the terms of the Creative Commons Attribution License, which permits unrestricted use, distribution, and reproduction in any medium, provided the original author and source are credited. 


\section{Methods}

\section{Study design}

The study is a cross-sectional descriptive study.

\section{Study period}

The study period was from August to September 2014

\section{Study area}

The study area was OPD of No.2 Defence Services General Hospital, Naypyitaw.

\section{Participants}

All patients and attendants who came to OPD of No.2 Defence Services General Hospital.

\section{Sampling method}

Simple random sampling

\section{Sample size}

The sample size is 194 .

\section{Questionnaire}

The questionnaires were developed by slight modification of Beliefs about Medicines Questionnaire (BMQ) and used for the study. The questionnaires major domains were socio-demographic characteristic, perception and behavior on understanding of prescription.

\section{Pre-testing of questionnaire}

Pre-testing of the questionnaires in the study area was done by researcher in order to correct any inconsistency or anomalies or to add any suggestive points before finalizing instrument for data collection.

\section{Data collection}

Data was collected by using the structural questionnaires through face-to face interview. The interview time for each participant was taken at least 30 minutes.

\section{Data analysis plan}

After data collection, the data was edited, coded and entered by using SPSS version 20. Associations between estimates of groups were performed using the Chi-square test for proportions.

\section{Ethical Considerations}

The ethical clearance was obtained from Ethical Review Board of DSMRC, Naypyitaw, Myanmar. Written consent was taken from all participants and the entire data was maintained confidential.

\section{Results}

\section{Social characteristics of the participants}

A total of 194 participants (99 males and 95 females) those who attended to outpatient department (OPD) participated in the structured questionnaire using face-to-face interview at Number 2 Defence Services General Hospital. Table 1 shows the socio-demographic characteristics of participants such as age, race, educational status and visit for whom in all participants at OPD. The participants were age between 17 and 77 years and the mean age was 47.27 (SD 11.67) years. Most of the participants were at the age of 50 to 59 years (35.6\%) and second highest was at the age of 40 and 49 years (26.3\%). Regarding education, the highest percent of the participants were in middle school level $(34.5 \%)$. About 23.7 percent $(n=46)$ were primary school level. Regarding race, most of the participants were Burmese (90.7\%) and the remainders were Shan, Kayin and others. The participants who they came to hospital for themselves (93.3\%), for husband / wife (2.1\%), for their children (1\%) and for parent (1.5\%) respectively.

\section{Patients' perspectives upon medical prescription}

Response to each perspective statement was given strongly agree, agree, uncertain, disagree and strongly disagree by using Likert scale, on medical prescription. Perception of the participants on the measurement scales were found to be mostly in positive scales (Table 2).

\section{Types of health care provider}

Table 3 shows that the participants visited the types of health care provider. Among the participants, $59.3 \%$ of participants visited to specialist doctors and other (25.8\%) visited to medical officers and the remainders (14.9\%) did not know who treated to them.70.4 percent were treated by physician, 9.6 percent were treated by surgeon, and 3.5 percent were treated by otolaryngologist and 2.6 percent were treated by orthopedic surgeon. The remainders (13.9\%) were treated by ophthalmologist, psychiatrist and physiatrist. Most of the persons who prescribed the patients how to take the pills were medical doctors (73.2\%). The others were pharmacist (22.2\%) and nurse (4.6\%). But most of the prescribers were graduate level $(47.4 \%)$ and postgraduate level $(47.4 \%)$, only $5.2 \%$ of prescribers $(n=10)$ were high school level.

\section{Patients' understanding upon medical prescription}

Table 4 shows patients' understanding upon medical prescription. However the participants $(87.6 \%)$ could answer their diagnosis correctly, $12.4 \%$ of the participants could not answer their diagnosis correctly. Sixty eight percent of the participants could explain about each pill roughly. Only $32 \%$ of the participants $(n=32)$ could not explain about each pill. Furthermore, the participants (92.3\%) knew about dosing frequency of one or more pills and the remainders $(7.7 \%)$ did not know about it. Similarly, the participants (93.2\%) knew about how many days to take pill and the remainders (6.8\%) did not know about it. The prescribers (74.7\%) did not explain adverse reaction of all pills; only $25.3 \%$ of prescribers explained it.

Association between patients' understanding of medical prescription and influencing factors

Response to each understanding of medical prescription question was rated as "0" score for incorrect answer and "1" score for correct answer. There are 5 questions in the questionnaire and therefore the score range from 0 to 5 . A total score was categorized below mean (0-3) was poor understanding and above mean (4-5) was good understanding. Percentages of students who fall into each of the category level were calculated. The score levels were cross-tabulated with influencing factors by using Chi-square tests to determine any significant association within participants.

Association between patients' understanding of medical prescription and influencing factors is shown in Table 5. It can be seen that $61.9 \%$ of participants have good understanding and $38.1 \%$ of participants have poor understanding. There was significant association between patients' understanding of medical prescription and age group of participants. It was concluded that the older age group were more understanding than lower age group. Association between patients' 
Citation: Chan N, Lin KS, Aung NC, Kyaw M, Khaing M, et al. (2016) Patients' Perspectives: Understanding of Medical Prescription. J Gen Pract 4: 233. doi: $10.4172 / 2329-9126.1000233$

Page 3 of 5

\begin{tabular}{|c|c|c|c|c|c|c|c|}
\hline & \multirow{2}{*}{ Category } & \multicolumn{2}{|c|}{ Male $(n=99)$} & \multicolumn{2}{|c|}{ Female $(n=95)$} & \multicolumn{2}{|c|}{ Total $(\mathrm{N}=194)$} \\
\hline & & Number & Percent & Number & Percent & Number & Percent \\
\hline \multirow{7}{*}{ Age } & $17-19$ years & 1 & $1.0 \%$ & 1 & $1.1 \%$ & 2 & $1.1 \%$ \\
\hline & $20-29$ years & 8 & $8.1 \%$ & 6 & $6.3 \%$ & 14 & $7.2 \%$ \\
\hline & $30-39$ years & 17 & $17.2 \%$ & 19 & $20 \%$ & 36 & $18.6 \%$ \\
\hline & $40-49$ years & 21 & $21.2 \%$ & 30 & $31.6 \%$ & 51 & $26.3 \%$ \\
\hline & $50-59$ year & 41 & $41.4 \%$ & 28 & $29.5 \%$ & 69 & $35.6 \%$ \\
\hline & $60-69$ year & 8 & $8.1 \%$ & 11 & $11.6 \%$ & 19 & $9.8 \%$ \\
\hline & $70-79$ year & 3 & $3 \%$ & 0 & 0 & 3 & $1.5 \%$ \\
\hline \multirow{4}{*}{ Educational status } & Primary & 18 & $18.2 \%$ & 28 & $29.5 \%$ & 46 & $23.7 \%$ \\
\hline & Middle & 31 & $31.3 \%$ & 36 & $37.9 \%$ & 67 & $34.5 \%$ \\
\hline & High & 38 & $38.4 \%$ & 20 & $21.1 \%$ & 58 & $29.9 \%$ \\
\hline & Graduate & 12 & $12.1 \%$ & 11 & $11.6 \%$ & 23 & $11.9 \%$ \\
\hline \multirow{4}{*}{ Race } & Burmese & 93 & $93.9 \%$ & 83 & $87.4 \%$ & 176 & $90.7 \%$ \\
\hline & Shan & 0 & $0 \%$ & 4 & $4.2 \%$ & 4 & $2.1 \%$ \\
\hline & Kayin & 0 & $0 \%$ & 2 & $2.1 \%$ & 2 & $1.0 \%$ \\
\hline & Others & 6 & $6.1 \%$ & 6 & $6.3 \%$ & 12 & $6.2 \%$ \\
\hline \multirow{5}{*}{ Visit for whom } & Themselves & 91 & $91.9 \%$ & 90 & $94.7 \%$ & 181 & $93.3 \%$ \\
\hline & Husband/ Wife & 2 & $2.0 \%$ & 2 & $2.1 \%$ & 4 & $2.1 \%$ \\
\hline & Parents & 2 & $2.0 \%$ & 1 & $1.1 \%$ & 3 & $1.5 \%$ \\
\hline & Their children & 1 & $1.1 \%$ & 1 & $1.0 \%$ & 2 & $1.0 \%$ \\
\hline & Others & 3 & $3.0 \%$ & 1 & $1.1 \%$ & 4 & $2.1 \%$ \\
\hline
\end{tabular}

Table 1: Social characteristics of the participants.

\begin{tabular}{|c|c|c|c|c|c|c|}
\hline No & Statement & Strongly agree & Agree & Uncertain & Disagree & $\begin{array}{l}\text { Strongly } \\
\text { disagree }\end{array}$ \\
\hline 1 & Doctors give many medicines for patients. & $54 ; 27.8 \%$ & $54 ; 27.8 \%$ & $22 ; 11.3 \%$ & $45 ; 23.2 \%$ & $19 ; 9.8 \%$ \\
\hline 2 & Most medicines are addictive & $26 ; 13.4 \%$ & $26 ; 13.4 \%$ & $19 ; 9.8 \%$ & $72 ; 37.1 \%$ & $51 ; 26.3 \%$ \\
\hline 3 & Patients usually obey medical prescription. & $120 ; 61.9 \%$ & $50 ; 25.8 \%$ & $10 ; 5.2 \%$ & $13 ; 5.2 \%$ & $1 ; 0.5 \%$ \\
\hline 4 & Most medicines give more side effects than advantage. & $11 ; 5.7 \%$ & $22 ; 11.3 \%$ & $37 ; 19.1 \%$ & $70 ; 36.1 \%$ & $54 ; 27.8 \%$ \\
\hline 5 & All medicines are poisons. & $6 ; 3.1 \%$ & $12 ; 6.2 \%$ & $15 ; 7.7 \%$ & $46 ; 23.7 \%$ & $115 ; 59.3 \%$ \\
\hline 6 & The doctors usually explain the disease of the patients. & $117 ; 60.3 \%$ & $63 ; 32.5 \%$ & $2 ; 1 \%$ & $9 ; 4.6 \%$ & $3 ; 1.5 \%$ \\
\hline 7 & $\begin{array}{l}\text { The doctors usually explain their patients how to take the } \\
\text { medicines. }\end{array}$ & $142 ; 73.2 \%$ & $48 ; 24.7 \%$ & $1 ; 0.5 \%$ & $1 ; 0.5 \%$ & $2 ; 1 \%$ \\
\hline 8 & The doctors usually explain side effects of medicines. & $70 ; 36.1 \%$ & $62 ; 32 \%$ & $5 ; 2.6 \%$ & $40 ; 20.6 \%$ & $17 ; 8.8 \%$ \\
\hline 9 & $\begin{array}{l}\text { The patients must ask when they do not understand medical } \\
\text { prescription. }\end{array}$ & $139 ; 71.6 \%$ & $47 ; 24.2 \%$ & $1 ; 0.5 \%$ & $3 ; 1.5 \%$ & $4 ; 2.1 \%$ \\
\hline 10 & Natural remedies are safer than medicines. & $16 ; 8.2 \%$ & $25 ; 12.9 \%$ & $80 ; 41.2 \%$ & $51 ; 26.3 \%$ & $22 ; 11.3 \%$ \\
\hline
\end{tabular}

Table 2: Patients' perspectives upon medical prescription.

\begin{tabular}{|c|c|c|c|c|c|c|c|}
\hline & \multirow{2}{*}{ Category } & \multicolumn{2}{|c|}{ Male $(n=99)$} & \multicolumn{2}{|c|}{ Female $(n=95)$} & \multicolumn{2}{|c|}{ Total $(\mathrm{N}=194)$} \\
\hline & & Number & Percent & Number & Percent & Number & Percent \\
\hline \multirow{3}{*}{$\begin{array}{l}\text { Types of medical } \\
\text { doctors }\end{array}$} & Medical officer & 24 & $24.2 \%$ & 26 & $27.4 \%$ & 50 & $25.8 \%$ \\
\hline & Specialist doctor & 60 & $60.6 \%$ & 55 & $57.9 \%$ & 115 & $59.3 \%$ \\
\hline & Don't know & 15 & $15.2 \%$ & 14 & $14.7 \%$ & 29 & $14.9 \%$ \\
\hline \multirow{5}{*}{$\begin{array}{c}\text { Types of Specialist } \\
\text { doctors }\end{array}$} & Physician & 40 & $66.7 \%$ & 41 & $74.5 \%$ & 81 & $70.4 \%$ \\
\hline & Surgeon & 4 & $6.7 \%$ & 7 & $12.7 \%$ & 11 & $9.6 \%$ \\
\hline & Otolaryngologist & 1 & $1.7 \%$ & 3 & $5.5 \%$ & 4 & $3.5 \%$ \\
\hline & Orthopedic surgeon & 2 & $3.3 \%$ & 1 & $1.8 \%$ & 3 & $2.6 \%$ \\
\hline & Others & 13 & $21.7 \%$ & 3 & $5.5 \%$ & 16 & $13.9 \%$ \\
\hline \multirow{3}{*}{$\begin{array}{l}\text { Types of medical } \\
\text { prescribers }\end{array}$} & Medical Doctor & 65 & $65.7 \%$ & 77 & $81.1 \%$ & 142 & $73.2 \%$ \\
\hline & Pharmacist & 27 & $27.3 \%$ & 16 & $16.8 \%$ & 43 & $22.2 \%$ \\
\hline & Nurse & 7 & $7.1 \%$ & 2 & $2.1 \%$ & 9 & $4.6 \%$ \\
\hline \multirow{3}{*}{$\begin{array}{c}\text { Educational status of } \\
\text { prescribers }\end{array}$} & High school & 4 & $4.0 \%$ & 6 & $6.3 \%$ & 10 & $5.2 \%$ \\
\hline & Graduate & 54 & $54.5 \%$ & 38 & $40.0 \%$ & 92 & $47.4 \%$ \\
\hline & Postgraduate & 41 & $41.4 \%$ & 51 & $53.7 \%$ & 92 & $47.4 \%$ \\
\hline
\end{tabular}

Table 3: Types of Health care provider. 
Citation: Chan N, Lin KS, Aung NC, Kyaw M, Khaing M, et al. (2016) Patients' Perspectives: Understanding of Medical Prescription. J Gen Pract 4: 233. doi: $10.4172 / 2329-9126.1000233$

Page 4 of 5

\begin{tabular}{|c|c|c|c|c|c|c|c|}
\hline & \multirow{2}{*}{ Category } & \multicolumn{2}{|c|}{ Male $(n=99)$} & \multicolumn{2}{|c|}{ Female $(n=95)$} & \multicolumn{2}{|c|}{ Total $(\mathrm{N}=194)$} \\
\hline & & Number & Percent & Number & Percent & Number & Percent \\
\hline \multirow{2}{*}{ Can you answer your diagnosis? } & Yes & 84 & $84.8 \%$ & 86 & $90.5 \%$ & 170 & $87.6 \%$ \\
\hline & No & 15 & $15.2 \%$ & 9 & $9.5 \%$ & 24 & $12.4 \%$ \\
\hline \multirow{2}{*}{ Can you explain about each pill? } & Yes & 63 & $63.6 \%$ & 69 & $72.6 \%$ & 132 & $68 \%$ \\
\hline & No & 36 & $36.4 \%$ & 26 & $27.4 \%$ & 62 & $32 \%$ \\
\hline \multirow{2}{*}{ Can you explain dosing frequency of pills? } & Yes & 89 & $89.9 \%$ & 90 & $94.7 \%$ & 179 & $92.3 \%$ \\
\hline & No & 10 & $10.1 \%$ & 5 & $5.3 \%$ & 15 & $7.7 \%$ \\
\hline \multirow[b]{2}{*}{ Do you know how many days to take pill? } & Yes & 91 & $91.9 \%$ & 90 & $94.7 \%$ & 181 & $93.2 \%$ \\
\hline & No & 8 & $8.1 \%$ & 5 & $5.3 \%$ & 13 & $6.8 \%$ \\
\hline \multirow[b]{2}{*}{ Did prescribers explain side effects of pills? } & Yes & 25 & $25.3 \%$ & 24 & $25.3 \%$ & 49 & $25.3 \%$ \\
\hline & No & 74 & $74.7 \%$ & 71 & $74.7 \%$ & 145 & $74.7 \%$ \\
\hline
\end{tabular}

Table 4: Patients understanding upon medical prescription.

\begin{tabular}{|c|c|c|c|c|}
\hline & $\begin{array}{c}\text { Good Understanding } 120 \\
(61.9 \%)\end{array}$ & $\begin{array}{c}\text { Poor Understanding } 74 \\
(38.1 \%)\end{array}$ & Total $194(100 \%)$ & $P$ value \\
\hline \multicolumn{5}{|l|}{ Age group of participants } \\
\hline Less than or equal 20 & $0(00.0 \%)$ & $2(100 \%)$ & $2(100 \%)$ & \multirow{4}{*}{$0.008^{*}$} \\
\hline $21-40$ years & $24(46.2 \%)$ & $28(53.8 \%)$ & $52(100 \%)$ & \\
\hline $41-60$ years & $85(69.7 \%)$ & $37(30.3 \%)$ & $122(100 \%)$ & \\
\hline 61 and above & $11(61.1 \%)$ & $7(38.9 \%)$ & $18(100 \%)$ & \\
\hline \multicolumn{5}{|l|}{ Gender of participants } \\
\hline Male & $54(54.5 \%)$ & $45(45.4 \%)$ & $99(100 \%)$ & $0.04^{*}$ \\
\hline Female & $66(69.5 \%)$ & $29(30.5 \%)$ & $95(100 \%)$ & \\
\hline \multicolumn{5}{|l|}{ Educational level of participants } \\
\hline Primary School & $29(63.0 \%)$ & $17(37.0 \%)$ & $46(100 \%)$ & 0.20 \\
\hline Secondary School & $36(53.7 \%)$ & $31(46.3 \%)$ & $67(100 \%)$ & \\
\hline High School & $37(63.8 \%)$ & $21(36.2 \%)$ & $58(100 \%)$ & \\
\hline Graduate & $18(78.3 \%)$ & $5(21.7 \%)$ & $23(100 \%)$ & \\
\hline \multicolumn{5}{|l|}{ Gender of prescribers } \\
\hline Male & $101(59.4 \%)$ & $69(40.6 \%)$ & $170(100 \%)$ & 0.06 \\
\hline Female & $19(79.2 \%)$ & $53(20.8 \%)$ & $24(100 \%)$ & \\
\hline \multicolumn{5}{|l|}{ Educational level of prescribers } \\
\hline High School & $4(40.0 \%)$ & $6(60.0 \%)$ & $10(100 \%)$ & 0.17 \\
\hline Graduate & $54(58.7 \%)$ & $38(41.3 \%)$ & $92(100 \%)$ & \\
\hline Post-graduate & $62(67.4 \%)$ & $30(32.6 \%)$ & $92(100 \%)$ & \\
\hline Time given for explanation of prescription & $107(60.8 \%)$ & $69(39.2 \%)$ & $176(100 \%)$ & 0.34 \\
\hline $1-10$ minutes & $13(72.2 \%)$ & $5(27.8 \%)$ & $18(100 \%)$ & \\
\hline $11-20$ minutes & & & & \\
\hline \multicolumn{5}{|l|}{ Doctor explain about patients' disease process } \\
\hline Explain & $111(63.8 \%)$ & $63(36.2 \%)$ & $174(100 \%)$ & 0.10 \\
\hline Do not explain & $9(45.0 \%)$ & $11(55.0 \%)$ & $20(100 \%)$ & \\
\hline & ${ }^{*} \mathrm{P}<0.05$ indicates statistically & ificance. & & \\
\hline
\end{tabular}

Table 5: Association between patients' understanding of prescription and influencing factors.

understanding of medical prescription and sex of participants is also shown in Table 5. It is indicated that $69.5 \%$ of female participants have good understanding of medical prescription. On the other hand, $54.5 \%$ of male participants fall in these levels. The difference is statistically significant.

There was no association between patients' understanding of medical prescription and other influencing factors such as educational status of participants, educational status of prescribers, gender of prescribers, explanation time of prescription and explanation about patients' disease process.

\section{Discussion}

A total of 194 participants (99 males and 94 females) who attended to outpatient department (OPD) participated by using face-to-face 
interview through the structured questionnaire. Most of participants visited to OPD for themselves. Over two-third of the participants were above 40 years old. So, we found that the older aged patients were more attended to OPD than younger aged patients. Regarding education, the most of the participants were in middle school level. Regarding race, most of the respondents were Burmese and the remainders were Shan, Kayin and others.

Perception of the respondents on medical prescription was found to be mostly in positive scales. Among the specialist treated participants, nearly two-third was treated by physician. The remainders were treated by surgeon, otolaryngologist, orthopedic surgeon, ophthalmologist, psychiatrist and physiotherapist. It was found that most of the participants were suffered from medical diseases.

However, most of the participants could answer their diagnosis correctly; the few participants could not answer it correctly. Nearly two-third of the participants could explain about each pill roughly. Over one-third of the participants could explain about each pill. Furthermore, most the participants knew about dosing frequency of one or more pills and the remainders did not know about it. Two-third of the prescribers did not explain adverse reaction of all pills; only onethird of prescribers explained it. Therefore, explanation about disease, side effect of the pills and frequency of taking pills must be promoted to the patients.

Regarding association between patients' understanding of medical prescription and influencing factors, the older age group has better understanding than the younger age group and statistically is significant. Moreover, the female participants who have better understanding than male participants and difference is statistically significant.

Though most of the participants understood medical prescription, nearly $10 \%$ of participants did not know or understand medical prescription. It may be due to the fact that, poor education and poor health knowledge tend to poor understanding of medical prescription. Therefore, we should promote education status at first, and then we must try to improve health knowledge and healthy behavior by combining inter-sectorial and intra-sectorial approach

\section{Conclusion and Recommendation}

In conclusion, though the doctors and nursing staffs are prescribing clearly and giving more time how to take the pills; some of the participants do not know it. Therefore, the prescribers should ask how to take the pills after the patients had received the pills and they also should explain adverse reaction of the pills. As knowledge and perception of medical prescription was still a problem in communities, should be given more explanation relating medical prescription, side effect of pills and how to take the pills.

The following recommendations should be done.

1. More time (at least ten minutes) should be given for medical prescription.

2. Short explanation about disease should be done.

3. Side effect of medical pills must be explained clearly.

4. Life style modifications should be supported to prevent medical disease.

5. Recheck must be done how to take the pills after the patients had received the pills.

6. Repetitions must be done about medical prescription if needs.

\section{Acknowledgements}

We would like to express our thanks to our commandant and the commandant from 2/1000 DSGH. We owe special thanks to participants who had actively cooperated and participated in the study. Lastly, we would like to thank our colleagues who provided continuous encouragement and support.

\section{References}

1. (2003) World Health Organization (WHO), Adherence to Long-Term Therapies: Evidence for Action (Geneva, Switzerland: WHO.

2. Reginster JY, Rabenda V, Neuprez A (2006) "Adherence, patient preference and dosing frequency: Understanding the relationship," Bone 38: S2-S6.

3. DiMatteo MR, Giordani PJ, Lepper HS, Croghan TW (2002) "Patient adherence and medical treatment outcomes: A meta-analysis," Medical Care 40: 794-811.

4. Ingersoll KS, Cohen J (2008) "The impact of medication regimen factors on adherence to chronic treatment: A review of the literature," Journal of Behaviora Medicine 31: 213-224.

5. Vermeire E, Hearnshaw H, Van Royen P, Denekens J (2001) "Patient adherence to treatment: Three decades of research. A comprehensive review," Journal of Clinical Pharmacy and Therapeutics 26: 331-342. 